\title{
An Iterative Approach to Depth Determination from Second Moving Average Residual Magnetic Anomalies
}

\author{
E.M. Abdelrahman, T.M. El-Araby and K.S. Essa \\ Geophysics Department, Faculty of Science, \\ Cairo University, Giza, Egypt
}

Received: 23/3/2003 Revised: 31/3/2004 Accepted: 21/9/2004

\begin{abstract}
We have developed a numerical method to estimate the depth of a buried structure from second moving average residual anomalies obtained from magnetic data using filters of successive graticule spacings. The problem of depth determination has been transformed into the problem of finding a solution to a nonlinear equation of the form $z=f(z)$. Formulas have been derived for a dike, horizontal cylinder, geologic contact, and a sphere. The method involves using simple models convolved with the same second moving average filters as applied to the observed magnetic data. As a result, our method can be applied not only to residuals but also to observed magnetic data. The method is applied to synthetic data with and without random errors. The validity of the method is tested in detail on a field example from Canada. In all cases examined, the depth obtained gives satisfied results with actual depth.
\end{abstract}

\section{Introduction}

Simple geometrical shaped models can be very useful in quantitative interpretation of magnetic data acquired in a small area over the buried structure. The models may not be geologically realistic, but useful approximate equivalence is sufficient to determine whether the form and magnitude of calculated magnetic effects are close enough to the observed magnetic data to make the geological postulate reasonable. However, very often the existence of interfering sources is a problem to use of quantitative methods of evaluation such as those given by Werner (1953), Gay (1963, 1965), Grant and West (1965), Hartman et al. (1971), Rao et al. (1973), Jain (1976), Stanley (1977), Atchuta Rao 
and Ram Babu (1980), Mohan et al. (1982), Thompson (1982), Prakasa Rao et al. (1986), Prakasa and Subrahmanyan (1988) and many others. It is, in circumstance such as these, that the interpretation of magnetic data must involve initial steps to remove unwanted field components in order to isolate the desired anomaly (e.g. regional-residual separation). The initial filtering operation include, for example, least-squares filtering techniques (Abdelrahman et al. 1985), Fourier transform methods (Syberg, 1972), regional susceptibility modeling methods (Li and Oldenberg, 1998), and two-coaxial structures analysis method (Abdelrahman et al. 2002). The derived local magnetic anomaly is then geologically interpreted to estimate the depth, often without properly accounting for uncertainties introduced by the filtering process. When filters are applied to observed data, they distort the shape and extension of the magnetic anomalies. Thus filtering magnetic anomalies generally yield unreliable geological interpretation.

On the other hand, few methods have been developed to determine the actual depth to a buried structure from filtered magnetic anomalies. These methods include, for example, the use of correlation factors between successive leastsquares residual magnetic anomalies (Abdelrahman, 1990), the use of a parametric relationship (Abdelrahman and Hassanein, 2000) and higher derivative analysis techniques (Abdelrahman and Abo-Ezz, 2001). However, effective quantitative interpretations using a numerical method based on the analytical expression of second moving average residual magnetic anomalies are yet to be developed.

The aim of the present paper is to introduce an interpretive technique based on using simple models convolved with same second moving average filter as applied to the measured magnetic data. Formulas are derived for a dike, horizontal cylinder, geologic contact, and a sphere. The validity of the method is tested on synthetic data with and without random error and also on a field example from Canada.

\section{Formulation of the Problem}

The magnetic anomaly expression produced by most geologic structures with center located at $x_{i}=0$ can be represented by the following function (Abdelrahman and Hassanein, 2000)

$$
\mathrm{H}\left(\mathrm{x}_{\mathrm{i}}, \mathrm{z}, \theta\right)=\mathrm{KW}\left(\mathrm{x}_{\mathrm{i}}, \mathrm{z}, \theta\right), \mathrm{i}=1,2, \ldots \mathrm{N},
$$

where

$$
\mathrm{W}\left(\mathrm{x}_{\mathrm{i}}, \mathrm{z}, \theta\right)=\left\{\frac{\left(\mathrm{az} \mathrm{z}^{2 \mathrm{r}}+\mathrm{bx}_{\mathrm{i}}^{2}\right)(\sin \theta)^{\mathrm{m}}(\cos \theta)^{\mathrm{n}}+\mathrm{cx}_{\mathrm{i}} \mathrm{z}^{\mathrm{p}}(\sin \theta)^{\mathrm{n}}(\cos \theta)^{\mathrm{m}}}{\left(\mathrm{x}_{\mathrm{i}}^{2}+\mathrm{z}^{2}\right)^{\mathrm{q}}}\right\},
$$


where $\mathrm{z}$ is the depth, $\mathrm{K}$ is the magnetization intensity, $\theta$ is the magnetization inclination in the vertical plane perpendicular to the strike of the structure and $\mathrm{x}$ is a horizontal position coordinates, and the numerical values of a, b, c, p, r, n, m, and $\mathrm{q}$ are defined in Table 1. Parameters $\mathrm{K}$ and $\theta$ define the components of the magnetic anomaly being measured (Gay, 1963 and 1965; Prakasa Rao et al., 1986; and Prakasa Rao and Subrahmanyan, 1988). Examples of $K$ and $\theta$ for the vertical $(\Delta \mathrm{V})$, horizontal $(\Delta \mathrm{H})$ and total-field $(\Delta \mathrm{T})$ anomalies for the case of thin dikes and horizontal cylinders are given in Table 2. In this Table, $\mathrm{k}$ is the magnetic susceptibility contrast, $\mathbf{I}_{\mathbf{0}}$ is the true inclination of the geomagnetic field, $\mathbf{H}_{\mathbf{o}}^{\prime}$ and $\mathbf{I}_{\mathrm{o}}^{\prime}$ are, respectively, the effective intensity and effective inclination of the geomagnetic field in the vertical plane normal to the strike of the body, $t$ and $\mathrm{d}$ are, respectively, the thickness and the dip of the dike, $\mathrm{S}$ is the cross-sectional area of the horizontal cylinder, and $\alpha$ is the azimuth of the body measured in the clockwise direction from the magnetic north.

TABLE 1. Definition of a, b, c, m, n, p, r, and q values shown in equation (1). F.H.D. and S.H.D. are the first and the second horizontal derivatives of the magnetic anomaly respectively (after Abdelrahman and Hassanein, 2000).

\begin{tabular}{|c|c|c|c|c|c|c|c|c|c|}
\hline Model & Magnetization & $\mathrm{a}$ & $\mathrm{b}$ & $\mathrm{c}$ & $\mathrm{m}$ & $\mathrm{n}$ & $\mathrm{p}$ & $\mathrm{r}$ & $\mathrm{q}$ \\
\hline Sphere & Vertical & 2 & -1 & -3 & 1 & 0 & 1 & 1 & 2.5 \\
\hline Sphere & Horizontal & -1 & 2 & -3 & 0 & 1 & 1 & 1 & 2.5 \\
\hline $\begin{array}{c}\text { Horizontal cylinder } \\
\text { Dike (F.H.D.) } \\
\begin{array}{c}\text { Geologic contact } \\
\text { (S.H.D.) }\end{array}\end{array}$ & $\begin{array}{c}\text { Total, vertical, } \\
\text { horizontal }\end{array}$ & 1 & -1 & 2 & 0 & 1 & 1 & 1 & 2 \\
\hline Dike & Total, vertical, & 1 & 0 & 1 & 0 & 1 & 0 & 0.5 & 1 \\
\hline
\end{tabular}

Table 2. Characteristic magnetization intensity $\mathrm{K}$ and magnetization inclination $\theta$ in Vertical $(\Delta \mathrm{V})$, Horizontal $(\Delta \mathrm{H})$ and Total $(\Delta \mathrm{T})$ magnetic anomalies due to thin dikes and horizontal cylinders (after Gay, 1963, 1965).

\begin{tabular}{|c|c|c|c|c|}
\hline \multirow[b]{2}{*}{$\begin{array}{c}\text { Anomaly } \\
\text { (H) }\end{array}$} & \multicolumn{2}{|c|}{ Thin dikes } & \multicolumn{2}{|c|}{ Horizontal cylinders } \\
\hline & $\begin{array}{l}\text { Magnetization } \\
\text { intensity } \\
(\mathrm{K})\end{array}$ & $\begin{array}{l}\text { Magnetization } \\
\text { inclination } \\
(\theta)\end{array}$ & $\begin{array}{l}\text { Magnetization } \\
\text { intenity } \\
(\mathrm{K})\end{array}$ & $\begin{array}{l}\text { Magnetization } \\
\text { inclination } \\
(\theta)\end{array}$ \\
\hline$\Delta \mathrm{V}$ & $2 \mathrm{kt} \mathbf{H}_{\mathbf{0}}^{\prime} / \mathrm{z}$ & $\mathbf{I}_{\mathbf{0}}^{\prime}-\mathrm{d}$ & $2 \mathrm{k} \mathbf{H}_{\mathbf{0}}^{\prime} \mathrm{S} / \mathrm{z}^{2}$ & $\mathbf{I}_{\mathbf{0}}^{\prime}-90^{\circ}$ \\
\hline$\Delta \mathrm{H}$ & $2 \mathrm{kt} \mathbf{H}_{\mathbf{o}}^{\prime} \sin \alpha / \mathrm{z}$ & $\mathbf{I}_{\mathbf{o}}^{\prime}-\mathrm{d}-90^{\circ}$ & $2 \mathrm{k} \mathbf{H}_{\mathbf{0}}^{\prime} \mathrm{S} / \mathrm{z}^{2} \sin \alpha$ & $\mathbf{I}_{\mathbf{o}}^{\prime}-180^{\circ}$ \\
\hline$\Delta \mathrm{H}$ & $\frac{2 \mathrm{k} \mathrm{t} \mathbf{H}_{\mathbf{o}}^{\prime} \sin \mathbf{I}_{\mathbf{0}}}{\mathrm{z} \sin \mathbf{I}_{\mathbf{o}}^{\prime}}$ & $2 \mathbf{I}_{\mathbf{o}}^{\prime}-\mathrm{d}-90^{\circ}$ & $2 \mathrm{k} \mathbf{H}_{\mathbf{o}}^{\prime} \mathrm{S} / \mathrm{z}^{2} \frac{\sin \mathbf{I}_{\mathbf{0}}}{\sin \mathbf{I}_{\mathbf{0}}^{\prime}}$ & $2 \mathbf{I}_{\mathbf{o}}^{\prime}-180^{\circ}$ \\
\hline
\end{tabular}


The first moving average (grid) method is an important and very simple technique for separation of potential field data into residual and regional components (Abdelrahman and El-Araby, 1993). The basic theory of the first moving average is described by Griffin (1949) and the application of leastsquares is described by Agocs (1951). However, the use of second moving average method for separation of magnetic anomalies into residual and regional components is yet to be developed.

Consider five observation points $x_{i}-2 s, x_{i}-s, x_{i}, x_{i}+s, x_{i}+2 s$, on the anomaly profile where $\mathrm{s}=1,2,3, \ldots, \mathrm{M}$ spacing units and is called graticule spacing or window length. The first moving average regional magnetic anomaly $\mathrm{Z}_{1}\left(\mathrm{x}_{\mathrm{i}}, \mathrm{z}, \theta, \mathrm{s}\right)$ is defined as the average of $\mathrm{H}\left(\mathrm{x}_{\mathrm{i}}+\mathrm{s}, \mathrm{z}, \theta\right)$ and $\mathrm{H}\left(\mathrm{x}_{\mathrm{i}}-\mathrm{s}, \mathrm{z}, \theta\right)$

$$
\mathrm{Z}_{1}\left(\mathrm{x}_{\mathrm{i}} \mathrm{z}, \theta, \mathrm{s}\right)=\frac{\mathrm{K}}{2}\left\{\mathrm{~W}\left(\mathrm{x}_{\mathrm{i}}+\mathrm{s}, \mathrm{z}, \theta\right)+\mathrm{W}\left(\mathrm{x}_{\mathrm{i}}-\mathrm{s}, \mathrm{z}, \theta\right\} .\right.
$$

The first moving average residual magnetic anomaly $\mathrm{R}_{1}\left(\mathrm{x}_{\mathrm{i}}, \mathrm{z}, \mathrm{q}, \mathrm{s}\right)$ is defined as $\mathrm{H}\left(\mathrm{x}_{\mathrm{i}}, \mathrm{z}, \theta\right)-\mathrm{Z}_{1}(\mathrm{xi}, \mathrm{z}, \theta, \mathrm{s})$ or

$$
\mathrm{R}_{1}\left(\mathrm{x}_{\mathrm{i}}, \mathrm{z}, \theta, \mathrm{s}\right)=\frac{\mathrm{K}}{2}\left\{2 \mathrm{~W}\left(\mathrm{x}_{\mathrm{i}}, \mathrm{z}, \theta\right)-\mathrm{W}\left(\mathrm{x}_{\mathrm{i}}+\mathrm{s}, \mathrm{z}, \theta\right)-\mathrm{W}\left(\mathrm{x}_{\mathrm{i}}-\mathrm{s}, \mathrm{z}, \theta\right)\right\} .
$$

The second moving average regional magnetic anomaly $Z_{2}\left(x_{i}, z, \theta, s\right)$ is defined as the average of $\mathrm{R}_{1}\left(\mathrm{x}_{\mathrm{i}}+\mathrm{s}, \mathrm{z}, \theta, \mathrm{s}\right)$ and $\mathrm{R}_{1}\left(\mathrm{x}_{\mathrm{i}}-\mathrm{s}, \mathrm{z}, \theta, \mathrm{s}\right)$

$$
\begin{aligned}
\mathrm{Z}_{2}\left(\mathrm{x}_{\mathrm{i}}, \mathrm{z}, \theta, \mathrm{s}\right)= & \frac{\mathrm{K}}{4}\left\{2 \mathrm{~W}\left(\mathrm{x}_{\mathrm{i}}+\mathrm{s}, \mathrm{z}, \theta\right)-\mathrm{W}\left(\mathrm{x}_{\mathrm{i}}+2 \mathrm{~s}, \mathrm{z}, \theta\right)-2 \mathrm{~W}\left(\mathrm{x}_{\mathrm{i}}, \mathrm{z}, \theta\right)\right. \\
& \left.+2 \mathrm{~W}\left(\mathrm{x}_{\mathrm{i}}-\mathrm{s}, \mathrm{z}, \theta\right)-\mathrm{W}\left(\mathrm{x}_{\mathrm{i}}-2 \mathrm{~s}, \mathrm{z}, \theta\right)\right\} .
\end{aligned}
$$

The second moving average residual magnetic anomaly $R_{2}\left(x_{i}, z, \theta, s\right)$ is defined as $\mathrm{R}_{1}\left(\mathrm{x}_{\mathrm{i}}, \mathrm{z}, \theta, \mathrm{s}\right)-\mathrm{Z}_{2}\left(\mathrm{x}_{\mathrm{i}}, \mathrm{z}, \theta, \mathrm{s}\right)$

$$
\begin{aligned}
\mathrm{R}_{2}\left(\mathrm{x}_{\mathrm{i}}, \mathrm{z}, \theta, \mathrm{s}\right)= & \frac{\mathrm{K}}{4}\left\{6 \mathrm{~W}\left(\mathrm{x}_{\mathrm{i}}, \mathrm{z}, \theta\right)-4 \mathrm{~W}\left(\mathrm{x}_{\mathrm{i}}+\mathrm{s}, \mathrm{z}, \theta\right)-4 \mathrm{~W}\left(\mathrm{x}_{\mathrm{i}}-\mathrm{s}, \mathrm{z}, \theta\right)\right. \\
& \left.+\mathrm{W}\left(\mathrm{x}_{\mathrm{i}}+2 \mathrm{~s}, \mathrm{z}, \theta\right)+\mathrm{W}\left(\mathrm{x}_{\mathrm{i}}-2 \mathrm{~s}, \mathrm{z}, \theta\right)\right\} .
\end{aligned}
$$

Equation (5) gives the following values at $x_{i}=0, x_{i}=s$, and $x_{i}=-s$, respectively,

$$
\begin{aligned}
\mathrm{R}_{2}(0)= & \frac{\mathrm{K}}{4}\{6 \mathrm{~W}(\mathrm{z}, \theta)-4 \mathrm{~W}(\mathrm{~s}, \mathrm{z}, \theta)-4 \mathrm{~W}(-\mathrm{s}, \mathrm{z}, \theta) \\
& +\mathrm{W}(2 \mathrm{~s}, \mathrm{z}, \theta)+\mathrm{W}(-2 \mathrm{~s}, \mathrm{z}, \theta)\}, \mathrm{x}_{\mathrm{i}}=0, \\
\mathrm{R}_{2}(\mathrm{~s})= & \frac{\mathrm{K}}{4}\{6 \mathrm{~W}(\mathrm{~s}, \mathrm{z}, \theta)-4 \mathrm{~W}(2 \mathrm{~s}, \mathrm{z}, \theta)-4 \mathrm{~W}(\mathrm{z}, \theta) \\
& +\mathrm{W}(3 \mathrm{~s}, \mathrm{z}, \theta)+\mathrm{W}(-\mathrm{s}, \mathrm{z}, \theta)\}, \mathrm{x}_{\mathrm{i}}=\mathrm{s}
\end{aligned}
$$


and

$$
\begin{aligned}
\mathrm{R}_{2}(-\mathrm{s})= & \frac{\mathrm{K}}{4}\{6 \mathrm{~W}(-\mathrm{s}, \mathrm{z}, \theta)-4 \mathrm{~W}(\mathrm{z}, \theta)-4 \mathrm{~W}(-2 \mathrm{~s}, \mathrm{z}, \theta) \\
& +\mathrm{W}(\mathrm{s}, \mathrm{z}, \theta)+\mathrm{W}(-3 \mathrm{~s}, \mathrm{z}, \theta), \mathrm{x}_{\mathrm{i}}=-\mathrm{s} .
\end{aligned}
$$

where

$$
\begin{aligned}
\mathrm{W}(\mathrm{z}, \theta) & =\left\{\frac{\mathrm{az}{ }^{2 \mathrm{r}}(\sin \theta)^{\mathrm{m}}(\cos \theta)^{\mathrm{n}}}{\left.\mathrm{z}^{2 \mathrm{q}}\right\},}\right. \\
\mathrm{W}( \pm \mathrm{s}, \mathrm{z}, \theta) & =\left\{\frac{\left(a z^{2 \mathrm{r}}+\mathrm{bs}^{2}\right)(\sin \theta)^{\mathrm{m}}(\cos \theta)^{\mathrm{n}} \pm \mathrm{scz}^{\mathrm{p}}(\sin \theta)^{\mathrm{n}}(\cos \theta)^{\mathrm{m}}}{\left(\mathrm{s}^{2}+\mathrm{z}^{2}\right)^{\mathrm{q}}}\right\}, \\
\mathrm{W}( \pm 2 \mathrm{~s}, \mathrm{z}, \theta) & =\left\{\frac{\left(a \mathrm{z}^{2 \mathrm{r}}+4 \mathrm{bs}^{2}\right)(\sin \theta)^{\mathrm{m}}(\cos \theta)^{\mathrm{n}} \pm 2 \mathrm{csz}^{\mathrm{p}}(\sin \theta)^{\mathrm{n}}(\cos \theta)^{\mathrm{m}}}{\left(4 \mathrm{~s}^{2}+\mathrm{z}^{2}\right)^{\mathrm{q}}}\right\}, \\
\mathrm{W}( \pm 3 \mathrm{~s}, \mathrm{z}, \theta) & =\left\{\frac{\left(a z^{2 \mathrm{r}}+9 b s^{2}\right)(\sin \theta)^{\mathrm{m}}(\cos \theta)^{\mathrm{n}} \pm 3 c s z^{\mathrm{p}}(\sin \theta)^{\mathrm{n}}(\cos \theta)^{\mathrm{m}}}{\left(9 \mathrm{~s}^{2}+\mathrm{z}^{2}\right)^{\mathrm{q}}}\right\}
\end{aligned}
$$

Using equations (6), (7) and (8), we obtain the following nonlinear equation in depth $(z)$

$$
\begin{aligned}
z= & {\left[F\left(\frac{\left(a z^{2 r}+b s^{2}\right)}{a\left(s^{2}+z^{2}\right)^{q}}-0.75 z^{2 r-2 q}-0.25 \frac{\left(a z^{2 r}+4 b s^{2}\right)}{a\left(4 s^{2}+z^{2}\right)^{q}}\right]\right.} \\
& \left.+1.25 \frac{\left(a z^{2 r}+b s^{2}\right)}{a\left(s^{2}+z^{2}\right)^{q}}-\frac{\left(a z^{2 r}+4 b s^{2}\right)}{a\left(4 s^{2}+z^{2}\right)^{q}}+0.25 \frac{\left(a z^{2 r}+9 b s^{2}\right)}{a\left(9 s^{2}+z^{2}\right)^{q}}\right]^{1 / 2 r-2 q}
\end{aligned}
$$

where

$$
\mathrm{F}=\frac{\mathrm{R}_{2}(\mathrm{~s})+\mathrm{R}_{2}(-\mathrm{s})}{\mathrm{R}_{2}(0)} .
$$

Equation (9) can be solved for $\mathrm{z}$ using the simple iteration method described by Demidovich and Maron (1973).

Knowing the depth $(\mathrm{z})$, the magnetization inclination $\theta$ can be determined from equations (7) and (8) 


$$
\theta=\tan ^{-1}\left[\left(\frac{\mathrm{M}}{c s z^{\mathrm{p}}}\right)^{3 a z^{2 r-2 q}-4 \frac{\left(a z^{2 r}+b s^{2}\right)}{\left(s^{2}+z^{2}\right)^{\mathrm{q}}}+\frac{\left(a z^{2 r}+4 b s^{2}\right)}{\left(4 s^{2}+z^{2}\right)^{\mathrm{q}}}}\right)^{\frac{1}{n-m}}-\frac{8}{\left(s^{2}+z^{2}\right)^{\mathrm{q}}}-\frac{3}{\left(4 s^{2}+z^{2}\right)^{\mathrm{q}}}+
$$

where

$$
M=\frac{R_{2}(s)-R_{2}( \pm s)}{R_{2}(0)} .
$$

Since $\mathrm{z}, \theta, \mathrm{s}$, and $\mathrm{R}_{2}(0)$ are known, the magnetization intensity $\mathrm{K}$ can be determined from equation (6)

$$
\mathrm{K}=\frac{2 \mathrm{R}_{2}(0)}{(\sin \theta)^{\mathrm{m}}(\cos \theta)^{\mathrm{m}}\left(3 \mathrm{az}{ }^{2 \mathrm{r}-2 \mathrm{q}}-4 \frac{\left(a z^{2 \mathrm{r}}+\mathrm{bs}^{2}\right)}{\left(\mathrm{s}^{2}+\mathrm{z}^{2}\right)^{\mathrm{q}}}+\frac{\left(\mathrm{az}^{2 \mathrm{r}}+4 \mathrm{bs}^{2}\right)}{\left(4 \mathrm{~s}^{2}+\mathrm{z}^{2}\right)^{\mathrm{q}}}\right)} .
$$

At this stage, we have assumed knowledge of the origin $\left(x_{i}=0\right)$. In practice, a field traverse will have an arbitrary origin, in which case the position of the structure $\left(\mathrm{x}_{\mathrm{i}}=0\right)$ in equation (1) must be first determined. In most cases, the main maximum value of the profile and the main minimum value of the profile can be used to obtain the correct location $x_{i}=0$. A straight line joining the maximum to the minimum of the profile will intersect the anomaly curve at the correct location $x_{i}=0$ (Stanley, 1977). The method is independent of base line determination because the magnetic data processing, equation (5), removes this effect.

\section{Theoretical Examples}

We computed three different composite magnetic fields, each consisting of the combined effect of a local structure (dike, horizontal cylinder, and sphere), and added a regional polynomial component. The model equations representing the model [equation (1)] and the regional anomalies are:

$$
\begin{aligned}
\mathrm{H}_{1}\left(\mathrm{x}_{\mathrm{i}}\right)= & 300 \frac{2 \cos 30^{\circ}+\mathrm{x}_{\mathrm{i}} \sin 30^{\circ}}{\mathrm{x}_{\mathrm{i}}^{2}+4} 2 \mathrm{x}_{\mathrm{i}}+50, \\
& \text { dike (total field) }+ \text { first-order regional }
\end{aligned}
$$




$$
H_{2}\left(x_{i}\right)=3000 \frac{\left(25-x_{i}^{2}\right) \cos 40^{\circ}+10 x_{i} \sin 40^{\circ}}{\left(x_{i}^{2}+25\right)^{2}}+0.05 x_{i}^{2}+3 x_{i}-50 \text {, }
$$

$$
\text { horizontal cylinder (total field) }+ \text { second-order regional }
$$

and

$$
\begin{gathered}
\mathrm{H}_{3}\left(\mathrm{x}_{\mathrm{i}}\right)=5000 \frac{\left(98-\mathrm{x}_{\mathrm{i}}^{2}\right) \sin 50^{\circ}-21 \mathrm{x}_{\mathrm{i}} \cos 50^{\circ}}{\left(\mathrm{x}_{\mathrm{i}}^{2}+49\right)^{2.5}}-0.0003 \mathrm{x}_{\mathrm{i}}^{3}-0.0015 \mathrm{x}_{\mathrm{i}}^{2}-0.09 \mathrm{x}_{\mathrm{i}}+1.5 \\
\text { sphere (vertical component) }+ \text { third-order regional. }
\end{gathered}
$$

It should be noted that the regional polynomial components in the above model equations are chosen arbitrary. The three composite magnetic anomalies are shown in Figure 1. In Figure 1, each composite anomaly $\mathrm{H}\left(\mathrm{x}_{\mathrm{i}}\right)$ is contaminated with $10 \%$ random error. Each noisy composite magnetic anomaly $\mathrm{H}$ $\left(\mathrm{x}_{\mathrm{i}}\right)$ was subjected to our new second moving average technique. Seven successive second moving average graticule spacings $(\mathrm{s}=2,3, \ldots, 8 \mathrm{~km})$ were applied to each set of input data using the following formula:

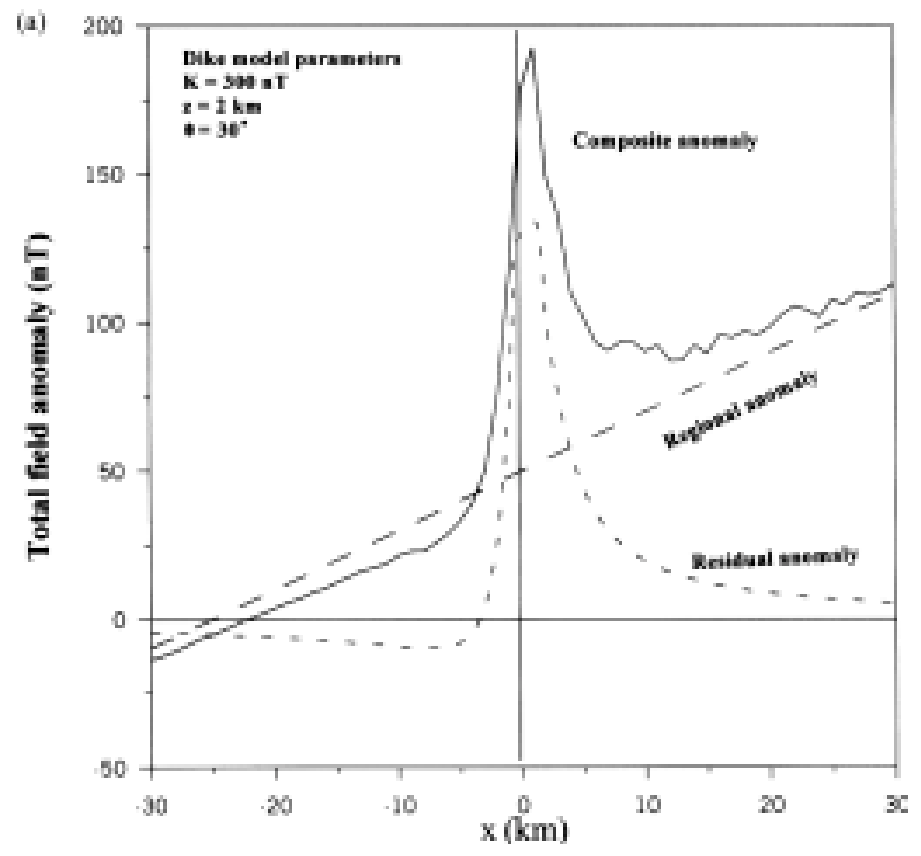

Fig. 1a

Fig. 1. Composite magnetic anomaly of (a) $\mathrm{H}_{1}$ of a buried dike and first-order regional as obtained from equation (12), (b) $\mathrm{H}_{2}$ from equation (13), and (c) $\mathrm{H}_{3}$ from equation (14). 


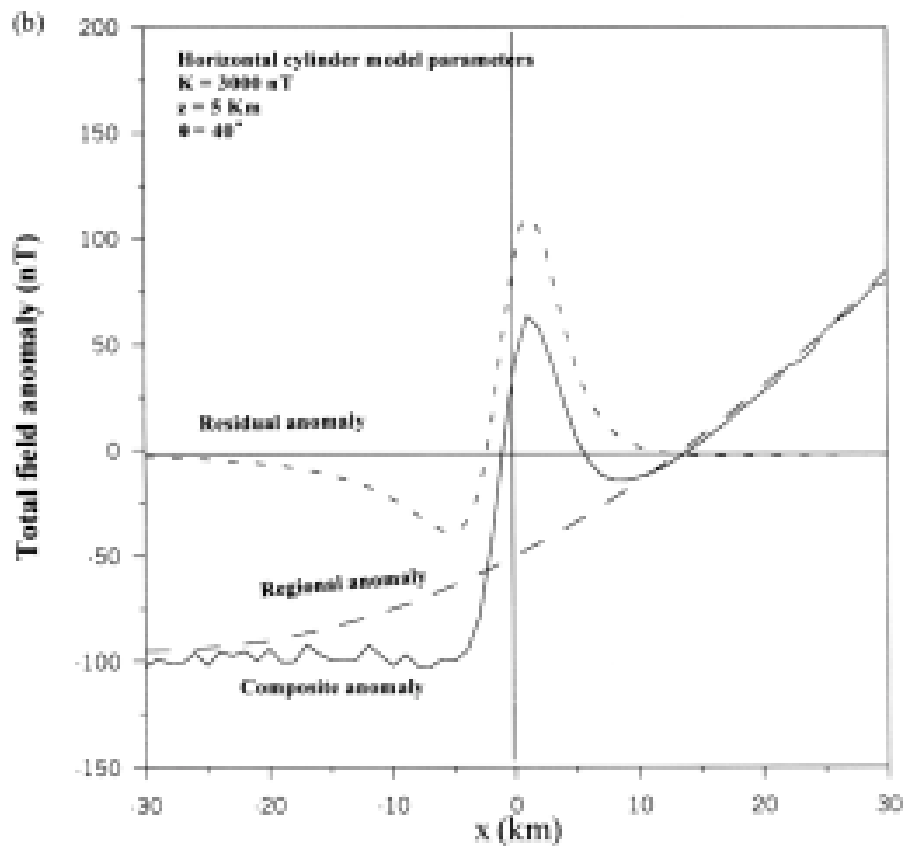

Fig. 1b

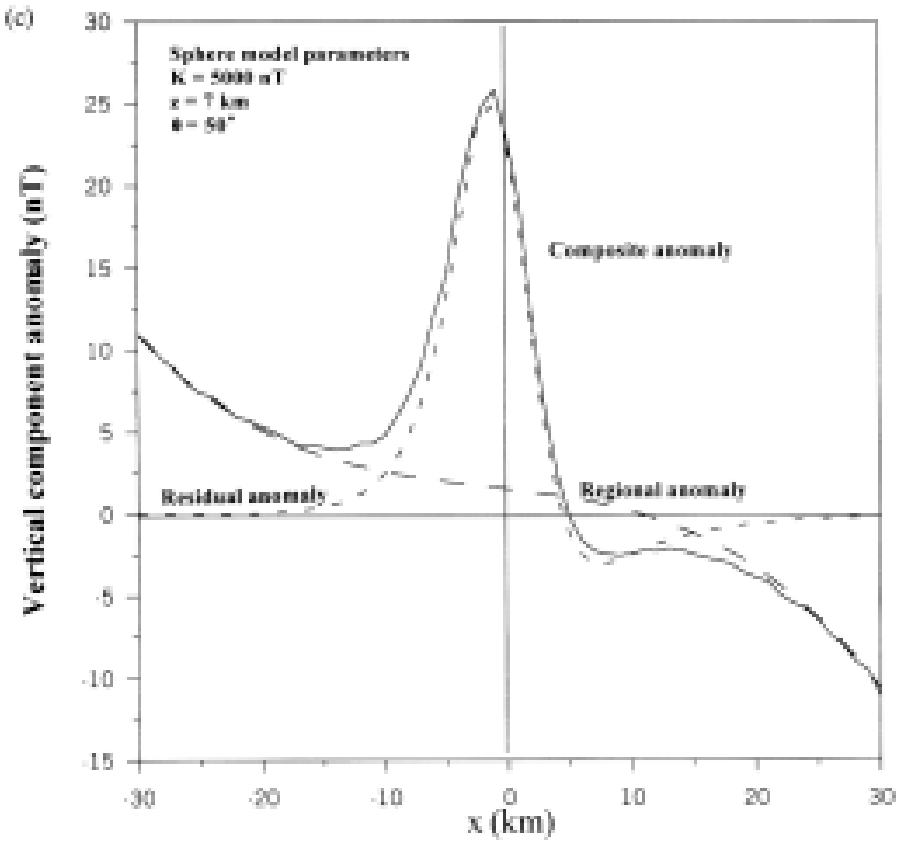

Fig. 1c 
$\mathrm{R}_{2}\left(\mathrm{x}_{\mathrm{i}}\right)=\frac{6 \mathrm{H}\left(\mathrm{x}_{\mathrm{i}}\right)-4 \mathrm{H}\left(\mathrm{x}_{\mathrm{i}}-\mathrm{s}\right)-4 \mathrm{H}\left(\mathrm{x}_{\mathrm{i}}+\mathrm{s}\right)+\mathrm{H}\left(\mathrm{x}_{\mathrm{i}}-2 \mathrm{~s}\right)+\mathrm{H}\left(\mathrm{x}_{\mathrm{i}}+2 \mathrm{~s}\right)}{4}$.

The second moving average residual magnetic anomalies thus obtained are shown in Figure 2. Each of the second moving average profiles was analyzed based on equations (9), (10), and (11). For each graticule spacing, the depth, magnetization inclination, and magnetization intensity values were determined. The results including the average values are given in Table 3.

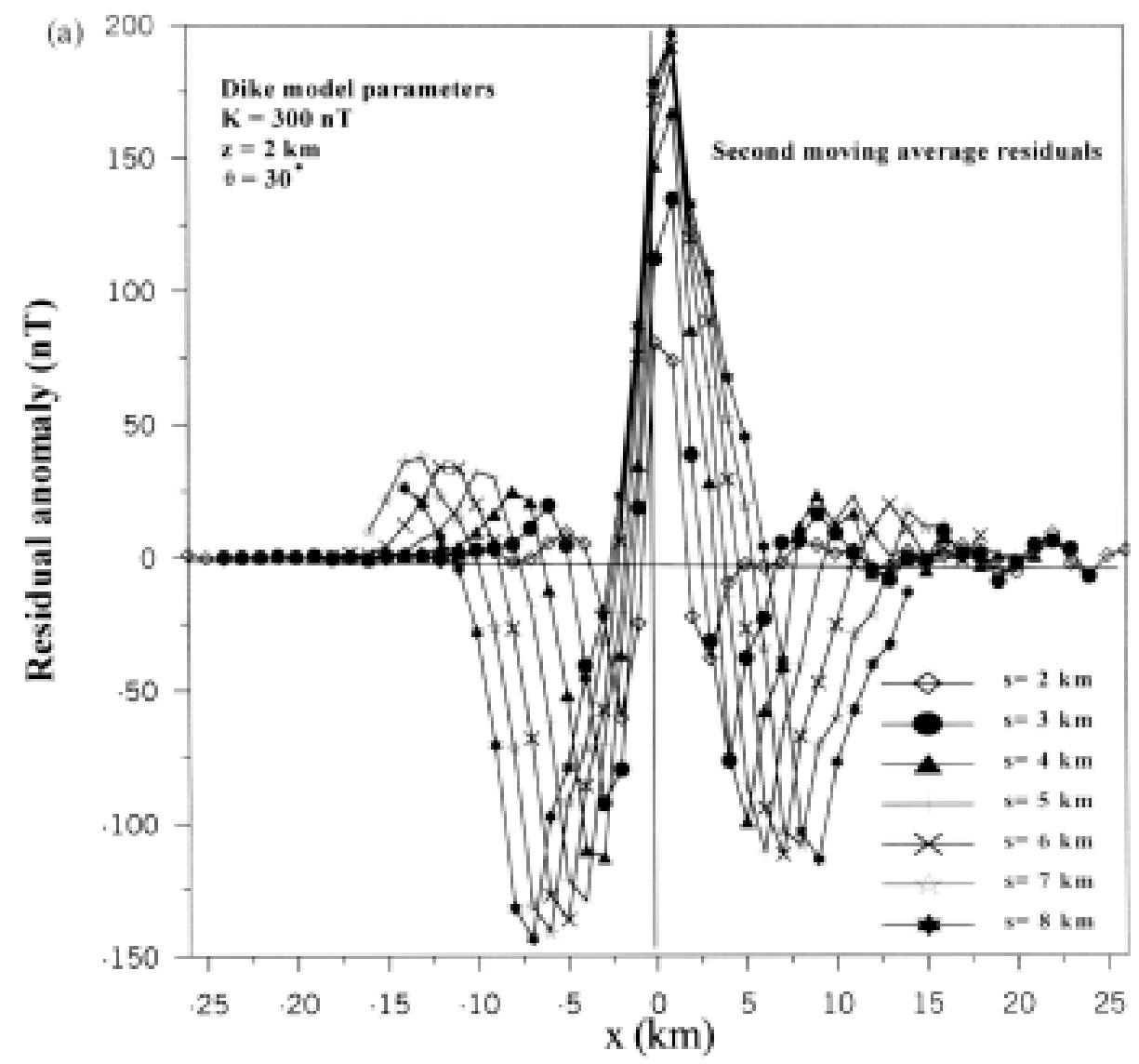

Fig. 2a

FIG. 2. Second moving average residual magnetic anomalies for $\mathrm{s}=2,3, \ldots, 8 \mathrm{~km}$ as obtained from magnetic anomalies (a) $\mathrm{H}_{1}$, (b) $\mathrm{H}_{2}$, and (c) $\mathrm{H}_{3}$. 


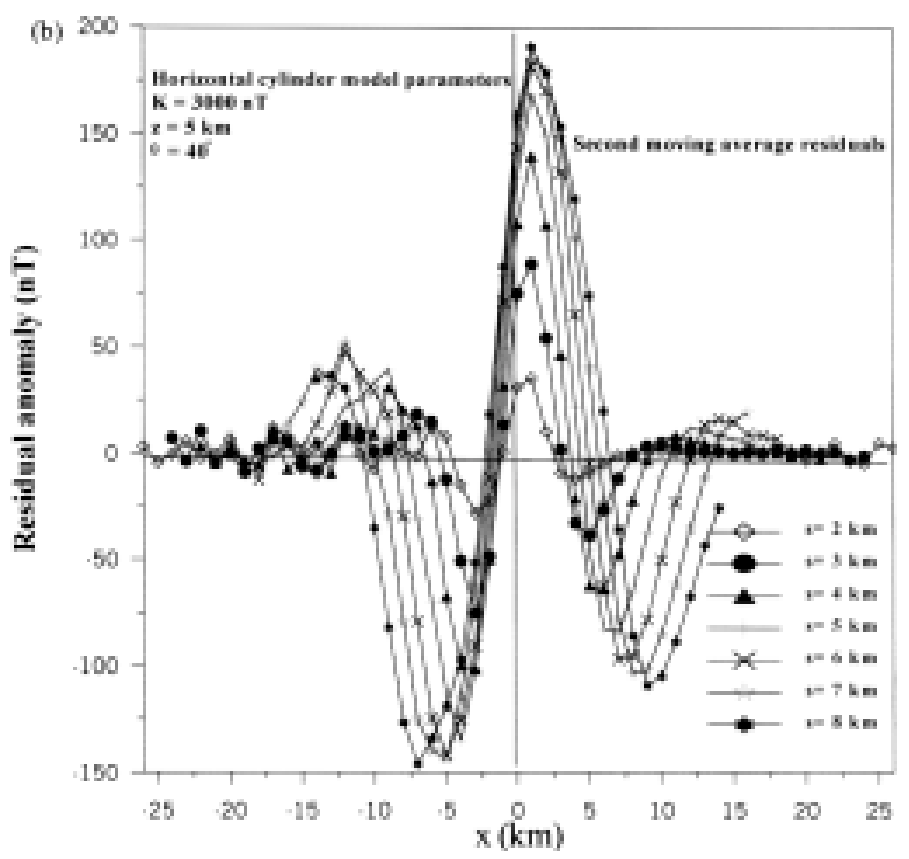

Fig. 2b

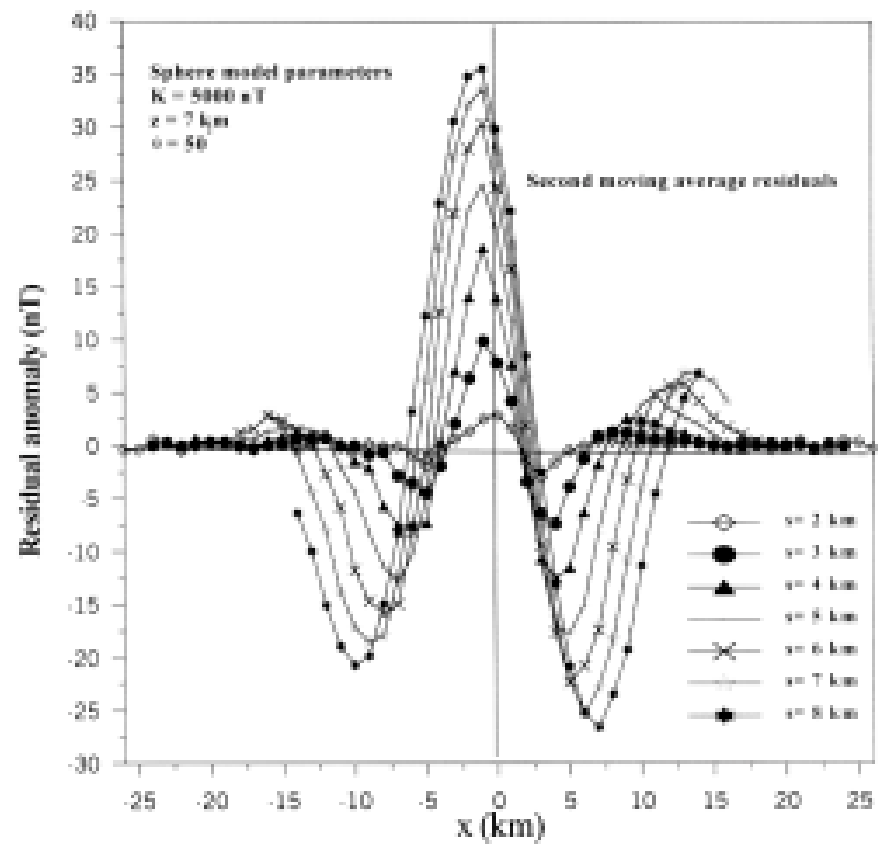

Fig. 2c 


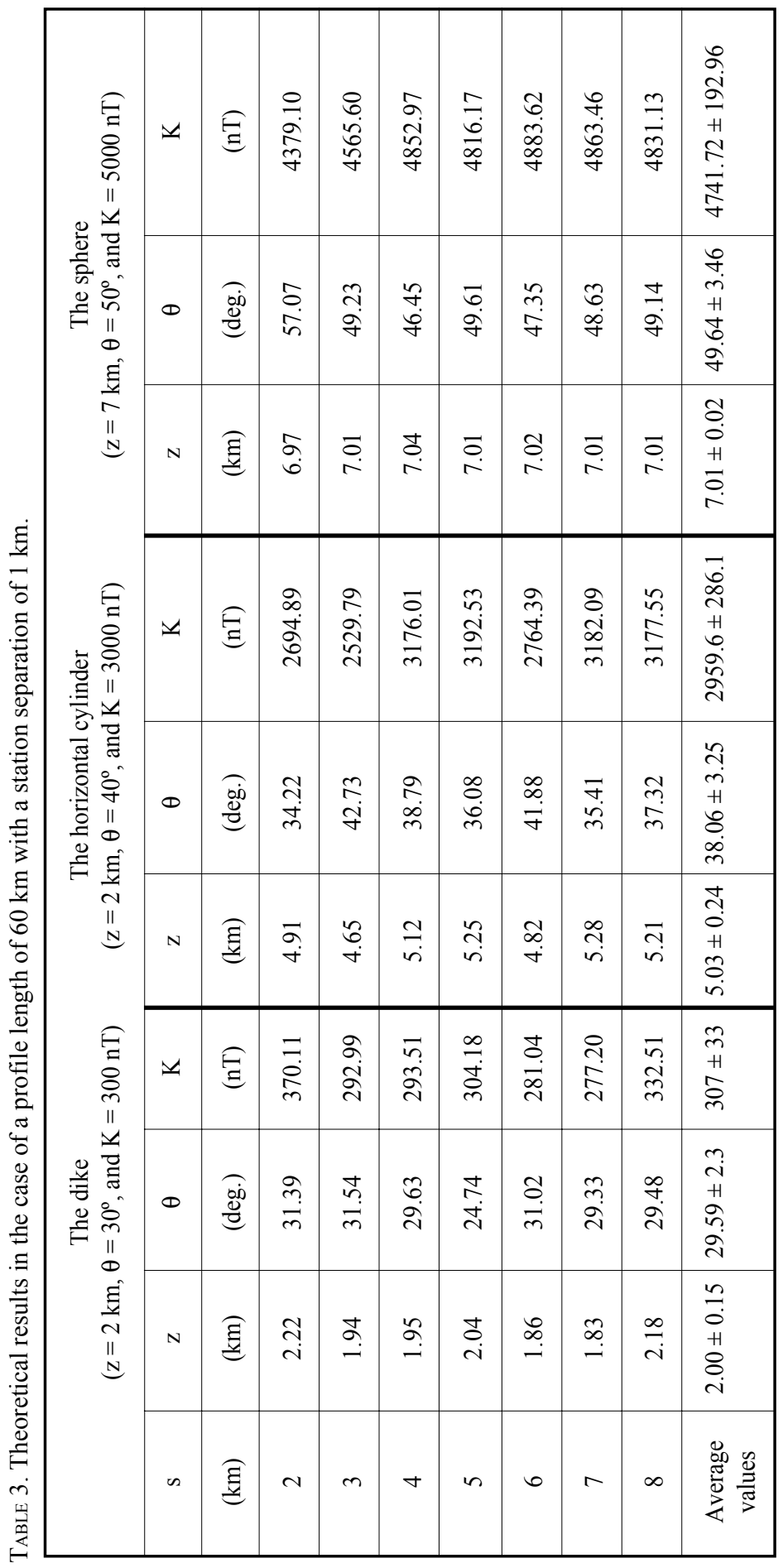


We verified numerically that the average values of the model parameters obtained by our method are in very good agreement with the actual model parameters given in equations (12), (13), and (14), and shown in Figure 1. The method works well even when the buried structure is located at shallow or deep depth with low or high magnetization inclination. Good results are obtained by using the present algorithm, particularly for depth estimation, which is a primary concern in magnetic prospecting and other geophysical work. The method is independent of the regional anomaly.

For synthetic data, we also verified that only a few points around $\mathrm{H}(0)$ are needed to obtain the exact values of $z, \theta$, and K. However, the data with error required more points around $\mathrm{H}(0)$.

\section{Field Example}

Figure 3 shows a total magnetic anomaly above an olivine diabase dike, Pishabo Lake, Ontario (McGrath and Hood, 1970). The depth to the outcropping dike (sensor height) is $304 \mathrm{~m}$ (Figure 3 ). The anomaly profile was digitized at an interval of $25 \mathrm{~m}$. The magnetic data were subjected to a separation technique using the second moving average method. Filters were applied for 10 successive graticule spacings $(\mathrm{s}=100,125, \ldots 325 \mathrm{~m})$ (Figure 4). The method, equations (9), (10), and (11) were applied to each of the 10 second moving average residual profiles to determine the model parameters assuming a dike target. The results are given in Table 4 . The average model parameters are: $\mathrm{z}=303 \mathrm{~m}, \theta=$ 37 degrees, and $\mathrm{K}=1072 \mathrm{nT}$. The depth obtained by the present method is in very good agreement with the actual depth $(304 \mathrm{~m})$.

\section{Conclusion}

The depth determination problem, assuming a simple buried structure, using second moving average residual magnetic anomalies has been transformed into the problem of finding a solution of a nonlinear equation of the form $z=f(z)$. Our method involves using simple models convolved with the same second moving average filter as applied to the observed data. As a result, our method can be applied not only to "true residual" but also to measured magnetic anomaly profiles. Synthetic and field studies demonstrate the efficiency of the present inversion technique where highly distorted residuals (Figures 2 and 4) yield reliable depth estimates.

\section{Acknowledgement}

The authors thank the editor and the two capable reviewers for their excellent suggestions, keen interest, valuable comments on the manuscript, and improvements to this work. 


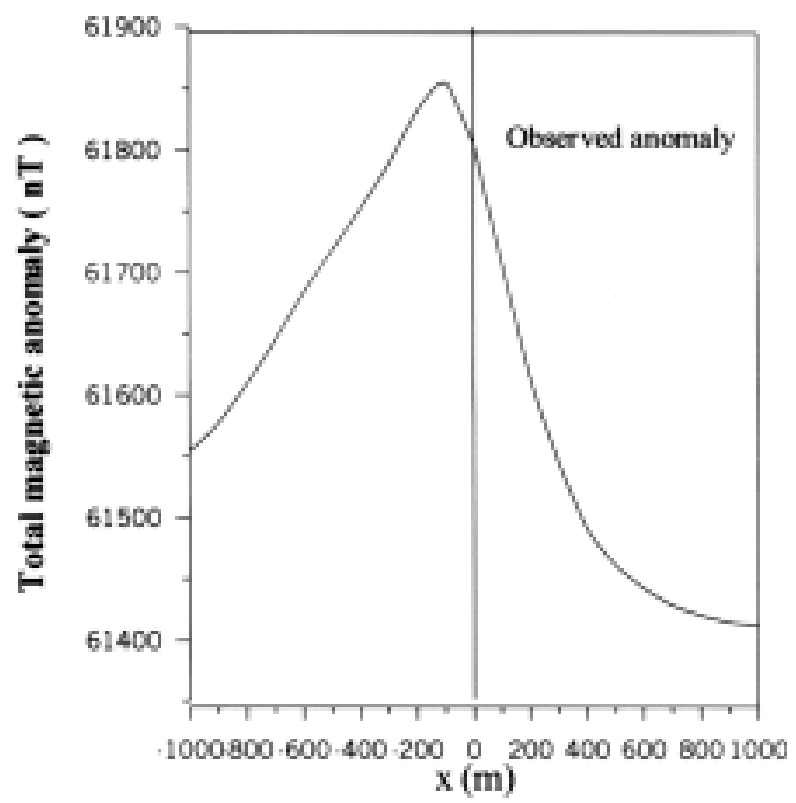

FIG. 3. Total magnetic anomaly over an outcropping olivine diabase dike, Pishabo Lake, Ontario, Canada (McGrath and Hood, 1970).

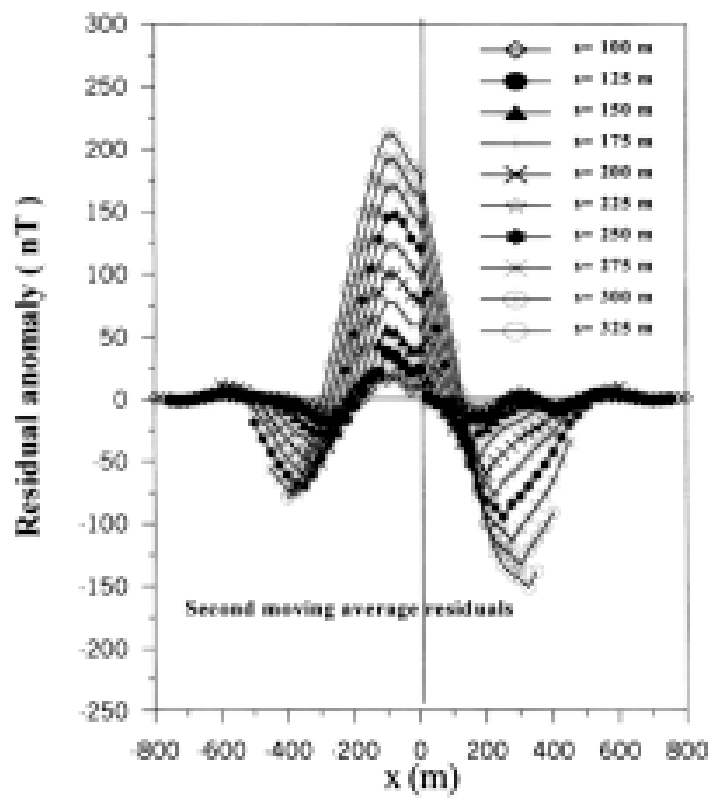

Fig. 4. Second moving average residual magnetic anomalies over an outcropping diabase dike, Pishabo Lake, Ontario, Canada for $\mathrm{s}=100,125, \ldots$. , and $325 \mathrm{~m}$. 
TABLE 4. Interpreted model parameters as computed from second moving average residual magnetic anomalies of olivine diabase like, Pishabo Lake, Ontario, Canada, using the present method.

\begin{tabular}{|c|c|c|c|}
\hline $\begin{array}{c}\mathrm{s} \\
(\mathrm{m})\end{array}$ & $\begin{array}{c}\mathrm{z} \\
(\mathrm{m})\end{array}$ & $\begin{array}{c}\theta \\
(\text { deg. })\end{array}$ & $\begin{array}{c}\mathrm{K} \\
(\mathrm{nT})\end{array}$ \\
\hline 100 & 315.56 & 52.04 & 1572.18 \\
\hline 125 & 301.19 & 47.69 & 1180.86 \\
\hline 150 & 300.50 & 41.18 & 1077.59 \\
\hline 175 & 300.84 & 36.52 & 1021.73 \\
\hline 200 & 309.41 & 33.06 & 1058.12 \\
\hline 225 & 302.06 & 31.82 & 963.44 \\
\hline 250 & 299.22 & 31.06 & 929.22 \\
\hline 275 & 294.89 & 31.71 & 909.09 \\
\hline 300 & 296.61 & 32.74 & 940.04 \\
\hline 325 & 311.89 & 34.11 & 1068.04 \\
\hline Average values & $303.2+6.78$ & $37.2+7.37$ & $1072.1+194.6$ \\
\hline
\end{tabular}

\section{References}

Abdelrahman, E.M. (1990) Magnetic interpretation of long horizontal cylinders using correlation factors between successive least-squares residual anomaly profiles: PAGEOPH, 132:521-532.

Abdelrahman, E.M. and El-Araby, T.M. (1993) A least-squares minimization approach to depth determination from moving average residual gravity anomalies: Geophysics, 59: 1779-1784.

Abdelrahman, E.M. and Hassanein, H.I. (2000) Shape and depth solutions from magnetic data using a parametric relationship: Geophysics, 65: 126-131.

Abdelrahman, E.M. and Abo-Ezz, E.R. (2001) Higher derivatives analysis of 2-D magnetic data: Geophysics, 66: 205-212.

Abdelrahman, E.M., Riad, S., Refai, E. and Amin,Y. (1985) On the least-squares residual anomaly determination: Geophysics, 50: 473-480.

Abdelrahman, E.M., El-Araby, H.M., El-Araby, T.M. and Essa, K.S. (2002) A new approach to depth determination from magnetic anomalies: Geophysics, 67: 1524-1531.

Agocs, W.B. (1951) Least-squares residual anomaly determination: Geophysics, 16: 686-696.

Atchuta Rao, D.A. and Ram Babu, H.V. (1980) Properties of the relation figures between the total, vertical, and horizontal field magnetic anomalies over a long horizontal cylinder ore body: Current Science, 49: 584-585.

Demidovich, B.P. and Maron, I.A. (1973) Computational mathematics: Mir. Publ.

Gay, P. (1963) Standard curves for interpretation of magnetic anomalies over long tabular bodies: Geophysics, 28: 161-200.

Gay, P. (1965) Standard curves for interpretation of magnetic anomalies over long horizontal cylinders: Geophysics, 30: 818-828. 
Grant, F.S. and West, G.F. (1965) Interpretation theory in applied geophysics, McGraw-Hill Book Company, NewYork, 584 p.

Griffin, W.R. (1949) Residual gravity in theory and practice: Geophysics, 14: 39-58.

Jain, S. (1979) An automatic method of direct interpretation of magnetic profiles: Geophysics, 41: $531-541$.

Hartman, R.R., Teskey, D.J. and Friedberg, J.L. (1971) A system for rapid digital aeromagnetic interpretation: Geophysics, 36, 891-918.

Li, Y. and Oldenburg, D.W. (1998) Separation of regional and residual magnetic field data: Geophysics, 63: 431-439.

McGrath, P.H. and Hood, P.J. (1970) The dipping dike case: A computer curve-matching method of magnetic interpretation: Geophysics, 35: 831-848.

Mohan, N. L., Sundararajan, N. and Seshagir Rao, S.V. (1982) Interpretation of some twodimensional magnetic bodies using Hilbert transforms: Geophysics, 46: 376-387.

Prakasa Rao, T.K.S. and Subrahmanyan, M. (1988) Characteristic curves for inversion of magnetic anomalies of spherical ore bodies: Pure and Applied Geophysics, 126: 69-83.

Prakasa Rao, T.K.S., Subrahmanyan, M. and Srikrishna Murthy, A. (1986) Nomograms for the direct interpretation of magnetic anomalies due to long horizontal cylinders: Geophysics, 51: 2156-2159.

Rao, B.S.R., Radhakrishna Murthy, I.V. and Visweswara Rao, C. (1973) A computer program for interpreting vertical magnetic anomalies of spheres and horizontal cylinders: Pure and Applied Geophysics, 110: 2056-2065.

Stanley, J.M. (1977) Simplified magnetic interpretation of the geologic contact and thin dike: Geophysics, 42: 1236-1240.

Syberg, F.J.R. (1972) A fourier method for the regional-residual problem of potential fields: Geophys. Prosp. 20: 47-75.

Thompson, D.T. (1982) EULDPH - a new technique for making computer-assisted depth estimates from magnetic data: Geophysics, 47: 31-37.

Werner, S. (1953) Interpretation or magnetic anomalies of sheet-like bodies. Sveriges Geologiska Underok, Series C 43: N6. 


\section{طريقـة تكراريـة لتحـديد العمـق من متوســ الحيـود المغناطيسية المتبقيـة من الرتبـة الثانيـة}

السيد محمد عبد الرحمن ، طارق محمد العربي و خالد سيد عيسى

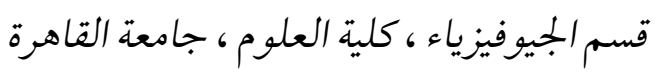

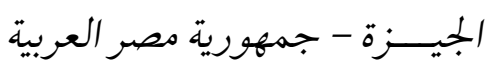

المستخلص · نستخدم في هذا البحث طريقة منحنيات النوافذ لتحديد

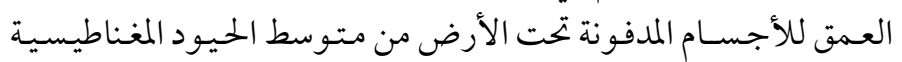

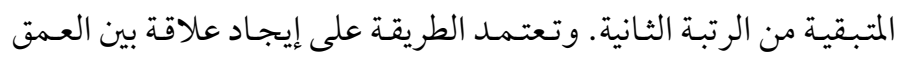

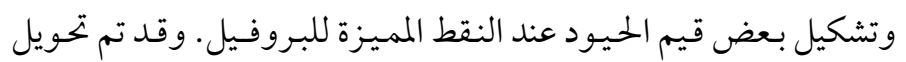

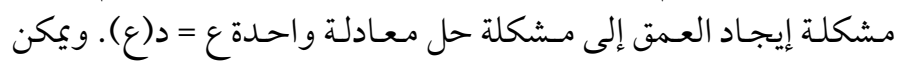

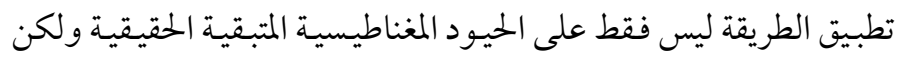

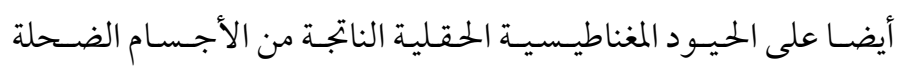
و العميقة.

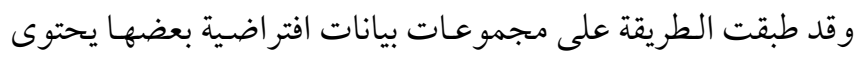

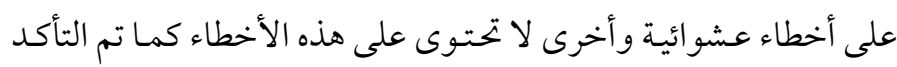

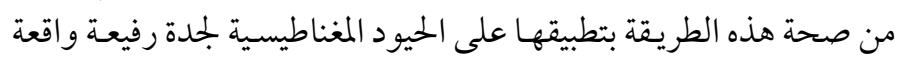
ببحيرة بشابو بكندا. 